\title{
Association between the Presence of Serumanti-Cardiolipin Antibodies and Infertility
}

\author{
Abdul-Razak Sh. Hasan1, Asmaa H. Hwaid2*, Zainab H. Mahdy² \\ ${ }^{1}$ Department of Microbiology, College of Medicine, Diyala University, Diyala, Iraq \\ ${ }^{2}$ Department of Biology, College of Education for Pure Science, Diyala University, Diyala, Iraq \\ Email: "asmaa.haseeb@ymail.com
}

Received 25 October 2015; accepted 12 January 2016; published 15 January 2016

Copyright (C) 2016 by authors and Scientific Research Publishing Inc.

This work is licensed under the Creative Commons Attribution International License (CC BY). http://creativecommons.org/licenses/by/4.0/

(c) (i) Open Access

\begin{abstract}
Background: Infertility is a common problem affecting $15 \%-20 \%$ of couples. The increased incidence of anticardiolipin (ACL) antibodies in infertile women supports the contention that these autoantibodies contribute to the infertility. Objectives: To investigate whether there is an association between the presence of serum ACL antibodies and infertility in both men and women in Diyala province. Subjects and methods: The present study was conducted in Baquba city for the period from October 2013 to November 2014. Subjects included in this study were chosen from those attending Baquba Teaching Hospital, Al-Batool Teaching Hospital for Maternity and Children and some Primary Health Care Centers in Baquba. The subjects were categorized as follows: 30 apparently healthy males with age ranged between (18 - 45) years; 30 apparently healthy women (age range: 18 - 47 years) had at least two live births without any miscarriages; 25 women (age range: 18 - 43 years) had reproductive failure for at least one year of marriage; 30 women (age range: 24 - 44 years) with at least one live birth had no pregnancy for at least two years after last child; 40 males with primary infertility (no children after at least five years of marriage and their active sperm count was zero). Detection of anti-ACL IgG and IgM was done using enzyme-linked immunosorbant assay (ELISA) commercial kits (Wendell/Shelm/Germany). All data were statistically analyzed. Results: The results revealed that the anti-ACL IgM positivity rate was significantly higher among women with primary fertility compared to healthy women $(p=0.006)$. Similarly, the anti-ACL IgM and anti-ACL IgG were significantly among women with secondary infertility compared to healthy women $(p=0.012)$ and $(p=0.038)$ respectively. Although the anti-ACL IgG and IgM positivity rate among men with primary infertility was higher than that of healthy control. However, the differences were failed to reach the statistical significance $(p=0.07)$ and $(p=0.31)$ respectively. Conclusion: The presence of high levels of anticardiolipin antibodies in
\end{abstract}

\footnotetext{
${ }^{*}$ Corresponding author.
}

How to cite this paper: Hasan, A.-R.Sh., Hwaid, A.H. and Mahdy, Z.H. (2016) Association between the Presence of Serumanti-Cardiolipin Antibodies and Infertility. Journal of Biosciences and Medicines, 4, 95-100. 
women with primary and secondary infertility as well as in men with primary infertility may support the contention that these autoantibodies contribute to the infertility in both sexes.

\author{
Keywords
}

\author{
Anticardiolipin Antibodies, Primary Infertility, Secondary Infertility
}

\title{
1. Introduction
}

Antiphospholipid antibodies (APA) comprise a heterogeneous group of antibodies of IgG, IgM and IgA classes, directed against anionic phospholipids and phospholipid-protein complexes [1]. Anticardiolipin antibodies (ACL) are most frequently determined antiphospholipid antibodies [2]. ACL are found in patients with systemic lupus erythematosus, antiphospholipid syndrome (APS), rheumatoid arthritis and some infectious diseases [3]. Within normal population, the frequency of ACL ranges between $1 \%$ in normal pregnancies and 5.6\%, in blood donors [4]. Increased levels of ACL were found in acute infections (up to 32\%), in rheumatoid arthritis (4\% - 25\%), in medication-induced lupus (47\%) and also in elder people without any characteristic symptoms (51\%) [5]. In most cases, their presence is accompanied with arterial and/or venous thrombosis and recurrent fetal loss [6]-[8]. However, further investigations demonstrated that ACL were directed against cardiolipin antigen complexed with a plasma protein as a cofactor, known as b2-glycoprotein I (b2-GPI) [9].

The concept of autoimmune basis of infertility is still controversial, particularly regarding the presence of ACL [10] [11]. It has been found that in fertile women, ACL was below the negative cut-off value, while women with unexplained infertility were positive in $23.8 \%$. ACL antibodies were detected in $21.5 \%$ of infertile male, most of them with unexplained infertility (15.4\%), suggesting that increased incidence of ACL in infertile women supports the contention that these autoantibodies contribute to the infertility [12]. It is generally accepted that the clinically relevant antiphospholipid antibodies bind to proteins with affinity for phospholipids, such as beta2-GPI. Following the attachment of beta2-GPI to trophoblast anionic phospholipid, both molecules undergo conformational changes resulting in the exposure of cryptic epitopes within the structure of beta2-GPI. This may allow the subsequent binding of antibodies hence affecting trophoblast functions directly. Moreover, anti-beta2GPI antibodies induce the activation of endothelial cells, resulting in a proinflammatory state which favors the prothrombotic diathesis of the syndrome [13].

Marai et al. (2004) [14] demonstrated a significant association between ACL and anti-antiphosphatidylserine with infertility compared to control parous women. Moreover, studies suggested a possible role of ACL in failure of implantation after in vitro fertilization and embryo transfer [14] [15].

\section{Subjects and Methods}

The present study was conducted in Baquba city (capital of Diyala province-Iraq) for the period from October/ 2013 to November 2014. Subjects included in this study were chosen from those attending Baquba Teaching Hospital, Al-Batool Teaching Hospital for Maternity and Children and some Primary Health Care Centers in Baquba. Special questionnaire was constructed to collect information regarding age, sex, residence, number of births. Each patient subject included in this study has to fill this questionnaire through a short personal interview. Human privacy was respected by oral consent has been taken from every participants.

The subjects were categorized in the following groups; (Healthy men group) 30 apparently healthy males (ages ranged between 18 - 45 years) were chosen by simple random selection from blood donors attending the Central Blood Bank in public Health laboratory-Baquba. (Healthy women group) 30 apparently healthy women (ages ranged between to 18 - 47 years) who had at least two live births without any miscarriages, they were non pregnant at the time of enrollment, they were chosen randomly during their usual attending to the outpatient consultant clinic. (Women with primary infertility group) 25 women (ages ranged between 18 - 43 years) had reproductive failure for at least one year of marriage. (Women with secondary infertility group) 30 women (ages ranged between 24 - 44 years) with at least one live birth and they had no pregnancy for at least two years after last child [16]. (Men with primary infertility group) 40males (ages ranged between 19 - 49 years) had no children after at least five years of marriage and their active sperm count was zero. Those males were selected during 
their attending to the outpatient clinic [17].

Whole venous blood was collected from each subject, centrifuged and sera was separated and kept frozen till use. Detection of anticardioilipin IgG and IgM were done using ELISA commercial kits (Wendell/shelm/Germany). The technique started by adding the tested serum into the microtiter plate wells which were already coated with cardiolipin, so the serum anticardiolipin IgG or IgM (If it present) bind to the cardiolipin on the solid phase. Upon addition of conjugate (anti-human IgG or IgM conjugated with the enzyme), it will complexed with the ACL IgG or IgM on the solid phase. A blue color developed upon addition of substrate and its intensity directly proportionate with the concentration of ACL in the serum.

All data were statistically analyzed using SPSS computer software. Frequency distributions for selected variables were done first. Mann-Whitney test is a non-parametric was applied to test the difference in median between 2 groups. The strength of association between variables was measured by Odd ratio (Risk factor). An estimate was considered significant if the $\mathrm{p}$ value was $<0.05$.

\section{Results}

The ACL IgM positivity rate among women with primary infertility was (24\%), while the positivity rate among the control group was $(0 \%)$. The difference between the two groups was statistically significant $(p=0.006)$. The risk (Odd ratio) of women with primary infertility to be positive ACL IgM was 20.3 times more than controls, Table 1.

Results in Table 2 showed that 6 (20\%) of women with secondary infertility were positive for ACL IgM. The positivity rate among the control group was $(0 \%)$. The difference between the two groups was statistically significant $(p=0.012)$. The results also revealed that the risk (Odd ratio) of women with secondary infertility to be ACL IgM positive was 16.2 times more than in control group.

The positivity rate of ACL IgG among women with secondary infertility was (13.3\%), while none of the control group gave positive result $(0 \%)$. The difference between the two groups was statistically significant $(\mathrm{p}=$ 0.038). The risk (Odd ratio) to be ACL IgG among women with secondary infertility was 10.4 times more than control group, Table 3.

The ACL IgG positivity rate among men with primary infertility was (10\%), which is higher than that in the control group (0\%). Although the risk to be ACL IgG positive in men with primary infertility was 7.5 times more than the controls; However, these increment was failed to reach the statistical significance ( $p=0.07)$, Table 4.

Table 5 revealed that the ACL IgM among men with primary infertility and controls was $10 \%$ and $3.3 \%$ respectively. The risk of men with primary infertility to be ACL IgM positive was 3.2 times more than in controls. The difference between the two groups was statistically insignificant $(p=0.31)$.

Table 1. Risk of ACL IgM in women with primary infertility.

\begin{tabular}{ccccc}
\hline \multirow{2}{*}{ ACL IgM } & \multicolumn{2}{c}{ Study groups } & Odd ratio & 95\% CI by Chi method \\
\cline { 2 - 3 } & Control & Primary infertility & & \\
Negative & $30(100 \%)$ & $19(76.0 \%)$ & 20.3 & $(2.32-117.98)$ \\
Positive & $0(0 \%)$ & $6(24.0 \%)$ & & \\
Total & $30(100 \%)$ & $25(100 \%)$ & \\
\hline
\end{tabular}

$X^{2}=7.406, \mathrm{p}=0.006[\mathrm{~S}]$.

Table 2. Risk of ACL IgM in women with secondary infertility.

\begin{tabular}{ccccc}
\hline \multirow{2}{*}{ ACL IgM } & \multicolumn{2}{c}{ Study group } & Odd ratio & 95\% CI by Chi method \\
\cline { 2 - 3 } & Control & Secondary infertility & & \\
Negative & $30(100 \%)$ & $24(80 \%)$ & 16.2 & $(1.87-140.41)$ \\
Positive & $0(0 \%)$ & $6(20 \%)$ & & \\
Total & $30(100 \%)$ & $30(100 \%)$ & \\
\hline
\end{tabular}

$X^{2}=6.376, p=0.012$ [S]. 
Table 3. Risk of ACL IgG in women with secondary infertility.

\begin{tabular}{ccccc}
\hline \multirow{2}{*}{ ACL IgG } & \multicolumn{2}{c}{ Study group } & Odd ratio & 95\% CI by Chi method \\
\cline { 2 - 3 } & Control & Secondary infertility & & \\
Negative & $30(100 \%)$ & $26(86.7 \%)$ & 10.4 & $(1.14-94.25)$ \\
Positive & $0(0 \%)$ & $49(13.3 \%)$ & $30(100 \%)$ & \\
Total & $30(100 \%)$ & & \\
\hline
\end{tabular}

$X^{2}=4.306, \mathrm{p}=0.038[\mathrm{~S}]$.

Table 4. Risk of ACL IgG in men with primary infertility.

\begin{tabular}{ccccc}
\hline \multirow{2}{*}{ ACL IgG } & \multicolumn{2}{c}{ Study group } & Odd ratio & 95\% CI by Chi method \\
\cline { 2 - 3 } & Control & Primary infertility & & \\
Negative & $30(100 \%)$ & $36(90 \%)$ & 7.5 & $(0.83-76.84)$ \\
Positive & $0(0 \%)$ & $4(10 \%)$ & \\
Total & $30(100 \%)$ & $40(100 \%)$ & \\
\hline
\end{tabular}

$X^{2}=3.233, \mathrm{p}=0.07$ [NS]

Table 5. Risk of ACL IgM in men with primary infertility.

\begin{tabular}{ccccc}
\hline \multirow{2}{*}{ ACL IgM } & \multicolumn{2}{c}{ Study group } & Odd ratio & 95\% CI by Chi method \\
\cline { 2 - 3 } & $29(96.7 \%)$ & Primary infertility & $36(90 \%)$ & 3.2 \\
Negative & $1(3.3 \%)$ & $4(10 \%)$ & & $(0.34-30.43)$ \\
Positive & $30(100 \%)$ & $40(100 \%)$ &
\end{tabular}

$X^{2}=1.043, p=0.31$ [NS].

\section{Discussion}

Infertility is a common problem affecting $15 \%$ - $20 \%$ of couples. Couples with primary infertility have never been able to conceive. While, secondary infertility is difficulty conceiving after already having conceived. In spite of the bulk knowledge about APA, the concept of autoimmune basis of infertility is still controversial, particularly regarding the presence of ACL [10] [11] [18].

In the present study, the significantly higher ACL IgM positivity rate in women with primary infertility was consistent with that reported by other workers [12] [14]. This may be due to the ability of ACL antibodies to cause tiny blood clots, preventing blood from flowing to the reproductive organs or placenta [6]-[8] [19]. It has been found that the passive transfer of the purified ACL IgM antibodies was associated with lower fecundity and/or an increased rate of embryo absorptions (equivalent to primary infertility) [20]. Moreover, ACL-mediated dysfunctions responsible for recurrent abortions could also inhibit fertilization, embryonic development, implantation or post-implantation/placental development [21] [22]. It is possible that endometrial infections (e.g. Chlamydia trachomatis or retrovirus) could represent primary immunization against phospholipids or phospholipid-binding proteins [22] [23].

The results revealed that the risk (Odd ratio) of women with secondary infertility to be ACL IgM antibody positive was 16.2 times more than in fertile women. This is in agreement with previous study reported that ACL IgM was detected in women with secondary infertility [12]. It has been a speculated that ACL IgM antibody may be associated with repeated in vitro fertilization/embryo transfer failures [15] [24] [25]. Furthermore, the occurrence of ACL antibodies in almost every second woman suffering from endometriosis suggests existing of autoimmunologic basis of the secondary infertility [26]. Autoimmunity is a possible cause of reproductive failure and infertility, since a prevalence of both organ and non-organ specific ACL has been documented in women with secondary infertility [21] [27]. Beside that the association between abnormal embryo morphology and the presence of ACL IgM antibody, may explain the low implantation rate and early pregnancy loss among women 
who attended in vitro fertilization [28].

The present study showed that the ACL IgG antibody positivity rate among men with primary infertility was (10\%), which is higher than that in the health fertile men. These results are in consistent with that of previous reports found that in infertile men with the presence of ACL IgG antibody, the sperms become clump, confused and unable to swim and consequently ineffective [29].

\section{Conclusion}

Unfortunately, for the best of our knowledge there were no previous studies on the relationship between the ACL IgM antibody and primary infertility in men. Therefore, further studies in this field are recommended to obey or deny the present results. However, eventually, the study concluded that the presence of high levels of anticardiolipin antibodies in women with primary and secondary infertility as well as in men with primary infertility may support the contention that these autoantibodies may contribute to the infertility in both sexes.

\section{References}

[1] McIntyre, J.A., Wanegenknecht, D.R. and Faulk, W.P. (2003) Antiphospholipid Antibodies: Discovery, Definitions, Detection and Disease. Progress in Lipid Research, 42, 176-237. http://dx.doi.org/10.1016/S0163-7827(02)00048-6

[2] Nash, M.J., Camilleri, R.S., Kunka, S., Mackie, I.J., Machin, S.J. and Cohen, H. (2004) The Anticardiolipin Assay Is Required for Sensitive Screening for Antiphospholipid Antibodies. Journal of Thrombosis and Haemostasis, 2, 10771081. http://dx.doi.org/10.1111/j.1538-7836.2004.00810.x

[3] Tincani, A., Casu, C., Cartella, S., Ziglioli, T. and Cattaneo, R. (2010) Antiphospholipid Antibody: Laboratory, Pathogenesis and Clinical Manifestations. Reumatismo, 62, 65-75.

[4] Al Jabri, A.A. and Al Buloshi, M.S. (2004) Anticardiolipin and Antinuclear Antibodies in the Adult Healthy Omani Individuals. Saudi Medical Journal, 25, 313-317.

[5] Slavica, M., Sneana, G. and Ljiljana, V. (2005) Formulation, Standardization and Validation of an ELISA Test for Determination of Anticardiolipin Antibodies. Jugoslovenska Medicinska Biohemija, 24, 135-139. http://dx.doi.org/10.2298/JMH0502135M

[6] Koike, T. (2000) Antiphospholipid Antibodies in Arterial Thrombosis. Annals of Medicine, 32, 27-31.

[7] Locht, H. and Wiik, A. (2006) IgG and IgM Isotypes of Anti-Cardiolipin and Anti-Beta2-Glycoprotein I Antibodies Reflect Different Forms of Recent Thrombo-Embolic Events. Clinical Rheumatology, 25, 246-250. http://dx.doi.org/10.1007/s10067-005-1166-x

[8] Hasan, A.Sh., Al-Duliami, A.A. and Al-Zubiadi, R.O. (2010) Serum Anti-Cardiolipin among Women with Recurrent Abortion in Diyala Province. Diyala Journal for Pure Sciences, 6, 86-95.

[9] Chighizola, C.B. and de Jesus, G.R. (2014) Antiphospholipid Antibodies and Infertility. Lupus, 23, 1232-1238. http://dx.doi.org/10.1177/0961203314529171

[10] Meroni, P.L., Gerosa, M., Raschi, E., Scurati, S., Grossi, C. and Borghi, M.O. (2008) Updating on the Pathogenic Mechanisms 5 of the Antiphospholipid Antibodies-Associated Pregnancy Loss. Clinical Reviews in Allergy \& Immunology, 34, 332-337. http://dx.doi.org/10.1007/s12016-007-8055-9

[11] Carp, H.J. and Shoenfeld, Y. (2007) Anti-Phospholipid Antibodies and Infertility. Clinical Reviews in Allergy \& Immunology, 32, 159-161. http://dx.doi.org/10.1007/s12016-007-0010-2

[12] Radojcic, L., Marjanovic, S., Vicovac, L. and Kataranovski, M. (2004) Anticardiolipin Antibodies in Women with Unexplained Infertility. Physiological Research, 53, 91-96.

[13] D’Ippolito, S., Di Simone, N., Di Nicuolo, F., Castellani, R. and Caruso, A. (2007) Antiphospholipid Antibodies: Effects on Trophoblast and Endothelial Cells. American Journal of Reproductive Immunology, 58, 150-158. http://dx.doi.org/10.1111/j.1600-0897.2007.00500.x

[14] Marai, I., Carp, H., Shai, S., Shabo, R., Fishman, G. and Shoenfeld, Y. (2004) Autoantibody Panel Screening in Recurrent Miscarriages. American Journal of Reproductive Immunology, 51, 235-240. http://dx.doi.org/10.1111/j.1600-0897.2004.00153.x

[15] Caccavo, D., Pellegrino, N.M., Lorusso, F., Capotorto, M., Vacca, M., Vimercati, A. and Depalo, R. (2007) Anticardiolipin Antibody Levels in Women Undergoing First in Vitro Fertilization/Embryo Transfer. Human Reproduction, 22, 2494-2500. http://dx.doi.org/10.1093/humrep/dem179

[16] Gurunath, S., Pandian, Z., Anderson, R.A. and Bhattacharya, S. (2011) Defining Infertility—A Systematic Review of Prevalence Studies. Human Reproduction Update, 17, 575-588. http://dx.doi.org/10.1093/humupd/dmr015 
[17] Cooper, T.G., Noonan, E., von Eckardstein, S., Auger, J., Baker, H.W., Behre, H.M., Haugen, T.B., Kruger, T., Wang, C., Mbizvo, M.T. and Vogelsong, K.M. (2010) World Health Organization Reference Values for Human Semen Characteristics. Human Reproduction Update, 16, 231-245. http://dx.doi.org/10.1093/humupd/dmp048

[18] Loncar, D. (2010) Anticardiolipin Antibodies in Pathogenesis of Infertility. Vojnosanitetski Pregled, 67, $216-219$. http://dx.doi.org/10.2298/VSP1003216L

[19] Shoenfeld, Y. and Blank, M. (2003) Autoantibodies Associated with Reproductive Failure. Lupus, 13, 643-648. http://dx.doi.org/10.1191/0961203304lu2009oa

[20] Glelcher, N. (1999) Reproductive Failure Prior to the Onset of Clinical Autoimmune Disease. Journal of Rheumatology, 38, 485-487. http://dx.doi.org/10.1093/rheumatology/38.6.485

[21] Adelowo, O.O. and Adetoro, O.O. (2010) Recurrent Pregnancy Loss and Antiphospholipid Syndrome: An Overlooked Association. African Journal of Medicine and Medical Sciences, 39, 227-231.

[22] Blank, M., Asherson, R.A., Cervera, R. and Shoenfeld, Y. (2004) Antiphospholipid Syndrome Infectious Origin. Journal of Clinical Immunology, 24, 12-23. http://dx.doi.org/10.1023/B:JOCI.0000018058.28764.ce

[23] Hu, L., Hornung, D., Kurek, R., Ostman, H., Blomberg, J. and Bergqvist, A. (2006) Expression of Human Endogenous Gamma Retroviral Sequences in Endometriosis and Ovarian Cancer. AIDS Research and Human Retroviruses, 22, 551-557. http://dx.doi.org/10.1089/aid.2006.22.551

[24] Zhong, Y.P., Ying, Y., Wu, H.T., Zhou, C.Q., Xu, Y.W., Wang, Q., Li, J., Sheng, X.T. and Li, J. (2011) Impact of Anticardiolipin Antibody on the Outcome of in Vitro Fertilization and Embryo Transfer. American Journal of Reproductive Immunology, 66, 504-509. http://dx.doi.org/10.1111/j.1600-0897.2011.01058.X

[25] Nam, Y.S., Cha, K.Y., Baek, J.Y., Kim, N.K., Kang, M.S. and Oh, D. (2002) A Study of Lupus Anticoagulants and Anticardiolipin Antibodies in Patients with Infertility and Recurrent Spontaneous Abortion. Korean Journal of Fertility and Sterility, 29, 29-35.

[26] Porter, T.F. (2001) Antiphospholipid Antibodies and Infertility. Journal of Clinical Gynecology and Obstetrics, 44, 2935.

[27] Gordon, C. (2004) Pregnancy and Autoimmune Diseases. Best Practice \& Research Clinical Rheumatology, 18, 359379.

[28] Azem, F., Geva, E., Amit, A., Lerner-Geva, L., Shwartz, T., Ben-Yosef, D. and Yovel, I. (1998) High Levels of Anticardiolipin Antibodies in Patients with Abnormal Embryo Morphology Who Attended an in Vitro Fertilization Program. American Journal of Reproductive Immunology, 39, 161-163. http://dx.doi.org/10.1111/j.1600-0897.1998.tb00349.x

[29] Choudhury, S.R. and Knapp, L.A. (2001) Human Reproductive Failure I: Immunological Factors. Journal of Human Reproduction Update, 7, 113-134. http://dx.doi.org/10.1093/humupd/7.2.113 